\title{
Reactive Oxygen Species and Tumor Metastasis
}

\author{
Doo Jae Lee ${ }^{1}$ and Sang Won Kang ${ }^{1,2, *}$
}

\begin{abstract}
The migration and invasion of cancer cells are the first steps in metastasis. Through a series of cellular responses, including cytoskeletal reorganization and degradation of the extracellular matrix, cancer cells are able to separate from the primary tumor and metastasize to distant locations in the body. In cancer cells, reactive oxygen species (ROS) play important roles in the migration and invasion of cells. Stimulation of cell surface receptors with growth factors and integrin assembly generates ROS, which relay signals from the cell surface to important signaling proteins. ROS then act within cells to promote migration and invasion. In this review, we collect recent evidence pointing towards the involvement of ROS in tumor metastasis and discuss the roles of ROS at different stages during the process of cancer cell migration, invasion and epithelial-mesenchymal transition.
\end{abstract}

\section{INTRODUCTION}

As the oxygen-derived reactive molecules, reactive oxygen species (ROS) include the superoxide anion $\left(\mathrm{O}_{2}^{-}\right)$, hydrogen peroxide $\left(\mathrm{H}_{2} \mathrm{O}_{2}\right)$, hydroxyl radical $(\mathrm{OH} \cdot)$, singlet oxygen $(\mathrm{O} \cdot)$ and ozone $\left(\mathrm{O}_{3}\right)$ in nature: in biological systems, the former three species are significant. The superoxide anion is not freely diffusible through the lipid membrane because of its negative charge, but probably can penetrate cells via anion channels. The superoxide anion attacks iron-sulfur centers in respiratory chains and iron-responsive proteins (Brazzolotto et al., 1999; Cairo et al., 1996). $\mathrm{H}_{2} \mathrm{O}_{2}$ is both membrane-permeable and relatively stable. Therefore, it reversibly oxidizes redox-sensitive proteins on methionine or cysteine residue. The methione oxidation to methione sulfoxide is reversed by methione sulfoxide reductase (Moskovitz et al., 1997). However, the cysteine oxidation is little complex: its oxidation to sulfenic or disulfide can be reduced by glutathione or thioredoxin, respectively; whereas, its hyperoxidation to sulfinic and sulfonic acids upon high $\mathrm{H}_{2} \mathrm{O}_{2}$ level can be reversed to the reduced cysteine by sulfiredoxin (Lowther and Haynes, 2011). Among the ROS, the hydroxyl radical is known to be the most reactive and toxic, and it rapidly attacks macromolecules, such as proteins, lipids, and nucleic acids, via a radical chain reaction.

Sources of intracellular ROS include the mitochondrial elec- tron transport chain, NADPH oxidases (NOX), cyclooxygenases (COX), and lipoxygenases (LOX) (Gloire et al., 2006). The mitochondrial electron transport chain produces ROS during aerobic respiration. The mitochondrial electron transport chain consists of four protein complexes (I-IV), where oxidationreduction events occur. The superoxide anion is principally produced from complex I and complex III (Bae et al., 2011). NOX enzymes actively produced superoxide anion at the expense of NADPH in mammalian cells (Lambeth, 2007). NOX is a multi-component, plasma membrane-coupled enzyme complex, which is comprised of membrane subunits (gp91phox and p22phox), and cytosolic proteins (p47phox, p67phox, and p40phox) along with the small guanosine triphosphate (GTP)binding protein Rac 1 and Rac 2 (Bae et al., 2011; Pervaiz and Clement, 2007). Using cytosolic NADPH as an electron donor, $\mathrm{O}_{2}^{-}$is generated via single electron reduction of $\mathrm{O}_{2}$ during the assembly of different NOX subunits.

As an abnormal balance in the intracellular levels of ROS interferes with cellular processes, cells neutralize excess ROS by means of antioxidant defense systems. Cellular antioxidant systems include superoxide dismutases (SOD1, SOD2, and SOD3), catalase, glutathiones, thioredoxins, glutathione peroxidases (GPx1, GPx2, GPx3, GPx4, and GPx5) (Arthur, 2000) and peroxiredoxins (Prx I, Prx II, Prx III, Prx IV, Prx V, and Prx VI) (Rhee et al., 2005). SODs constitute an important antioxidant enzyme that coverts $\mathrm{O}_{2}^{-}$to $\mathrm{H}_{2} \mathrm{O}_{2}$, which is then converted to water by either catalase or glutathione peroxidases or peroxiredoxins.

In cancer cells, high levels of ROS often overwhelm the antioxidant systems, leading to oxidative stress. Different levels of oxidative stress appear to induce different outcomes in cancer cells. Mild oxidative stress activates cell signaling mechanisms, such as proliferation, migration, and invasion, but high oxidative stress can induce cell death (Nishikawa, 2008). In this review, we discuss the latest progress made towards understanding the roles of ROS in cell migration, invasion, and epithelialmesenchymal transition (EMT).

\section{ROS AND MIGRATION}

Cell migration is an important process in physiological conditions like development and wound healing, and also in the pathological conditions, for example cancer cell invasion and

${ }^{1}$ Division of Life and Pharmaceutical Sciences and Research Center for Cellular Homeostasis, ${ }^{2}$ Department of Life Sciences, Ewha Womans University, Seoul 120-750, Korea

*Correspondence: kangsw@ewha.ac.kr 
metastasis (Hurd et al., 2012). It includes a wide array of cellular changes involving alterations in cell structure by regulation of cytoskeleton dynamics and expression of adhesion molecules. ROS are known to actively participate in all of the above events.

It is now well established that ROS are implicated in regulating many integrin-mediated cellular responses, such as adhesion, cytoskeleton organization, migration, proliferation, and differentiation. The integrin activation triggers a transient ROS production either independently or in cooperation with growth factor receptors (Chiarugi and Fiaschi, 2007; Sangrar et al., 2007; Ushio-Fukai, 2009). Although the mechanisms remain to be defined, there is clear evidence that integrin engagement with antibodies or extracellular matrix proteins produces cellular ROS by promoting changes in mitochondrial metabolic function (Kheradmand et al., 1998; Taddei et al., 2007; Werner and Werb, 2002) and activation of several oxidases, including NOX (Chiarugi et al., 2003; Honore et al., 2003; Sangrar et al., 2007), arachidonic acid (AA) metabolizing enzymes 5-lipoxygenase (5-LOX) (Chiarugi et al., 2003; Taddei et al., 2007), and cyclooxygenase-2 (COX-2) (Broom et al., 2006). Rac1 acts upstream of both NOX (Ushio-Fukai, 2009) and AA metabolizing

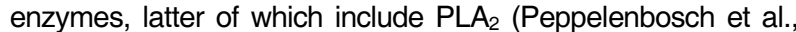
1995; Woo et al., 2000), 5-LOX (Chiarugi et al., 2003; Taddei et al., 2007; Woo et al., 2000), and COX-2 (Wu et al., 2007). Also, AA metabolism regulates NOX and mitochondrial ROS production, suggesting that Rac1 can activate complex networks of regulation for the ROS production (Gregg et al., 2004; Lee et al., 2006).

Recent evidence demonstrates that ROS play a major role in either the stabilization or destabilization of the cell-cell junction of VE-cadherin (Inumaru et al., 2009; Monaghan-Benson and Burridge, 2009; Thews et al., 2009; van Wetering et al., 2002). Rac1-induced ROS functions as a signaling molecule to disrupt VE-cadherin-based cell-cell adhesion, leading to various biological responses, such as endothelial barrier dysfunction and permeability change as well as endothelial migration and proliferation involved in angiogenesis (Lin et al., 2003; MonaghanBenson and Burridge, 2009; Nwariaku et al., 2004; van Wetering et al., 2002).

In addition, there is evidence for the involvement of Src and Pyk2 kinases in the phosphorylation of adherens junction proteins, including $\beta$-catenin and $p 120$-catenin, and the resulting loss of cell-cell adhesion was shown to be mediated by the Rac1-ROS signaling pathway (Inumaru et al., 2009; Lin et al., 2003; van Buul et al., 2005) (Fig. 1). Notably, it has been reported that antioxidant compounds can inhibit VEGF-induced angiogenesis through the disruption of ROS-dependent Src kinase activation and subsequent VE-cadherin tyrosine phosphorylation, thereby resulting in the retention of VE-cadherin at cell-cell contacts (Lin et al., 2003). Conversely, the cell contactdependent inhibition of cell growth and stimulation of protein tyrosine phosphatase activity (PTP) (Sorby and Ostman, 1996) have been associated with a decrease in the levels of intracellular ROS, and the consequent impairment of redox signaling mediated by growth factor receptors (Pani et al., 2000).

An interesting component of the Rac1-ROS signaling pathway, which plays an important role in the regulation of cadherin adhesive functions, is IQGAP, a scaffold protein involved in cellular motility and morphogenesis (Yamaoka-Tojo et al., 2006). IQGAP has been shown to be required for the establishment of VE-cadherin-based cell-cell contacts and to be colocalized with VE-cadherin at cell-cell contact sites (Yamaoka-Tojo et al., 2006). Besides biochemical modification of adherens junction molecules, the ROS-dependent regulation of cadherins may also be driven by transcriptional repression, as ROS induced hypermethylation of E-cadherin promoter by the upregulation of the transcriptional factor Snail and the recruitment of the DNA methyltransferase-1 (Yamaoka-Tojo et al., 2004).

\section{ROS AND INVASION}

An essential step in the tumor metastasis is breach of extracellular matrix $(\mathrm{ECM})$ and invasion of the surrounding stroma. The ECM-degrading enzymes pave the way for cancer cells to migrate to new sites. These proteases include the matrix metalloproteinases (MMPs), cathepsins, and urokinase plasminogen activator (UPA) (Brooks et al., 2010; Meyer and Hart, 1998). ROS have been implicated in the abnormal activation of these proteases in cancer cells. The signaling pathways activated by stimuli such as growth factors have been suggested to induce the invasive ability in cancer cells by increasing MMPs and uPA activities in a ROS-dependent manner (Kim et al., 2007; Nelson and Melendez, 2004; Tobar et al., 2010). The ROS-dependent intracellular pathways activated in relation to tumor invasion include MAPK signaling and regulation of transcription factors (NF-KB, ETS-1, Snail, AP-1) that lie upstream of MMPs and uPAs (Fig. 1).

The activities of MMPs are regulated by its endogenous inhibitors, known as the tissue inhibitors of metalloproteinases (TIMPs) (Curran et al., 2004; Lukaszewicz-Zajac et al., 2011). ROS-dependent regulation of MMPs is reported in several types of cancer cells, including breast cancer (Pelicano et al., 2009), glioblastoma (Chiu et al., 2010), and pancreatic cancer (Binker et al., 2009). ROS have been shown to directly regulate the expression and activity of MMPs or indirectly to regulate the blockade of TIMPs (Brenneisen et al., 2002; Kheradmand et al., 1998).

The NF-kB-induced MMP and UPA expressions have also been shown to be regulated by ROS produced from Nox and mitochondria (Nelson and Melendez, 2004; Pelicano et al., 2009; Shinohara et al., 2010; Tobar et al., 2010). Furthermore, the blockade of Nox by diphenyleneiodonium (DPI) abrogates NF- $\mathrm{KB}$ activation and inhibits MMP-9 expression, suggesting the role of ROS in NF-kB-induced MMPs expression (Shinohara et al., 2010). In addition, ETS-1 and AP-1 activation by ROS can control MMPs expression. The activated ERK and JNK facilitate the phosphorylation of ETS-1 and AP-1, respectively, leading to increased MMPs expression (Reddy and Mossman, 2002; Yang et al., 2003) (Fig. 1). It has been shown that the $\mathrm{H}_{2} \mathrm{O}_{2}$-mediated metastatic cascade includes the upregulation of MMP expression by AP-1 activation via the MAPK pathway (Ho et al., 2011). The small GTPase member, Ras, is also known to be involved in inducing MMPs expression (Yang et al., 2001). Interestingly, there was a report that Ras is activated by ROS-dependent oxidation at cystein-118 (Lander et al., 1995). Given that Ras is one of the upstream activators of MAPK, ROS-induced Ras may modulate MMPs through the MAPK pathway.

The UPA and UPAR have been shown to play a key role in many physiological processes, including embryogenesis, angiogenesis, wound healing, and tumor metastasis (Rabbani and Xing, 1998; Reuning et al., 2003). uPA is an extracellular protease that is activated upon binding to its receptor UPAR When activated UPA cleaves plasminogen, producing plasmin which degrades ECM components by proteolysis and also inducing the activation of MMPs. The activity of UPA is regulated by the plasminogen activator inhibitors (PAl-1 and PAl-2) 


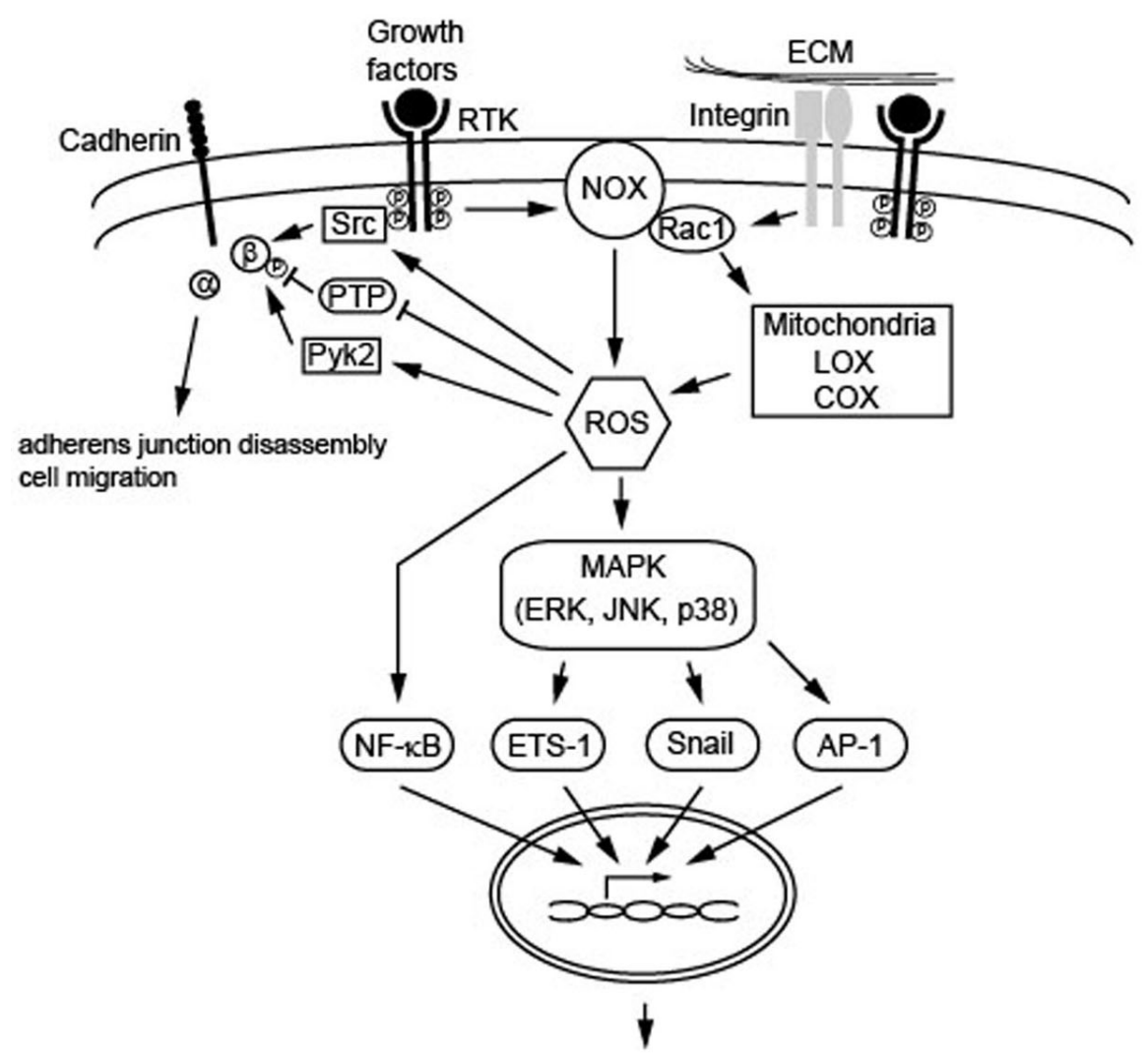

Fig. 1. Schematic summary of the ROS-mediated signaling cascades leading to EMT, migration, and invasion. Intracellular ROS may be produced from various sources, including NOX, Rac1, mitochondria, LOX, and COX as a result of stimulation of cell surface receptors with growth factors, as well as integrin assembly. ROS can influence cadherin adhesive functions through the PTP inhibition and/or the activation of Src and Pyk2 acting at adherens junctions. Also, ROS can activate the NF$\kappa B$ pathway and MAPK signaling cascade leading to activation of target genes, such as mesenchymal markers, MMPs, UPA, and, UPAR, and thereby be involved in the metastatic processes including EMT, migration and invasion.

Mesenchymal markers, MMPs, uPA, UPAR

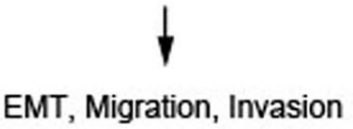

and the protease nexin-1 (Brooks et al., 2010; Meyer and Hart, 1998). Elevated levels of UPA and UPAR are observed in cancer cells, correlating with increased ROS levels and invasive phenotypes. ROS have been shown to control UPA and UPAR expression by activating its transcription factors, NF- $\mathrm{KB}$ and AP1 (Kim et al., 2007; Lee et al., 2009; Tobar et al., 2010) as well as by mRNA stabilization (Tran et al., 2003). Similar to MMPs expression, UPA and UPAR expression can also be induced by ROS in a MAPK-dependent manner (Kim et al., 2007; Lee et al., 2009) (Fig. 1).

\section{ROS AND EMT}

EMT is an important event during embryonic development as well as tumor metastasis. A number of signaling pathways involved in EMT are known to be activated during tumor metastasis (Giannoni et al., 2012). EMT is a biologic process allowing epithelial cells to undergo several biochemical alterations that permit the achievement of a mesenchymal phenotype. This is accompanied by a loss of epithelial markers (E-cadherin, laminin-1, ZO-1, desmoplakin, cytokeratin, and collagen IV), induction of mesenchymal markers ( $\mathrm{N}$-cadherin, $\alpha-S M A$, and vimentin), and upregulation of transcription factors (Snail, Slug, Twist, NF-kB, and Zeb). EMT is essential for migration and invasion of many cancer cells (Barnett et al., 2011; Baum et al.,
2008; Thiery and Sleeman, 2006). Recent studies have suggested the role of ROS in the induction of EMT in cancer cells. ROS can activate Snail and lead to EMT (Cannito et al., 2008; 2010; Dong et al., 2007) (Fig. 1). On the other hand, Snail has also been shown to regulate the ROS levels, as Snail overexpression in prostate cancer increases intracellular ROS levels (Barnett et al., 2011). This suggests a possible feedback mechanism by which ROS and Snail can regulate each other, and both events, leading to the induction of EMT.

The expression of genes implicated in hypoxia-induced EMT and angiogenesis may also be regulated by ROS. The transcription factor hypoxia-inducible factor 1-alpha (HIF-1 $\alpha$ ) is induced by hypoxia, and then activates the downstream transcription of EMT-related genes. Interestingly, under hypoxic conditions, ROS are produced due to the aberrant function of mitochondria complex III (Giannoni et al., 2012). ROS stabilize HIF- $1 \alpha$ by oxidative inhibition of the HIF-degrading enzyme prolyl hydroxylase (Comito et al., 2011). Moreover, under hypoxia conditions, EMT-related events, such as translocation of Snail to the nucleus, are found to be controlled by the levels of intracellular ROS (Cannito et al., 2008; Comito et al., 2011). Loss of intercellular adhesion is another important characteristic of EMT. ROS has been implicated in intercellular dissociation (Inumaru et al., 2009; Nigam et al., 1998). The p120-catenin family members are important cell-cell junctional proteins that 
stabilize catenins at the cell membrane (Anastasiadis and Reynolds, 2000). In an oxidative stress environment, tyrosine phosphorylation of $\mathrm{p} 120$-catenin results in its translocation to the cytoplasm (Inumaru et al., 2009), thus leading to intercellular dissociation accompanied by cytoskeletal remodeling. In addition, ROS scavengers inhibit $\mathrm{H}_{2} \mathrm{O}_{2}$-induced intercellular dissociation, demonstrating that ROS levels regulate cell adhesion (Inumaru et al., 2009; Nigam et al., 1998).

It has recently been reported that a connection between ROS and EMT is highlighted by a direct cross-talk between ROS and TGF- $\beta$ signaling. Upon TGF- $\beta$ stimulation, there is a significant increase of intracellular ROS, prevented by treatment of inhibitors of both NOX and mitochondrial electron transfer chain. TGF- $\beta$-dependent ROS release is then responsible for the phosphorylation of Smad2 and p38, which upregulate $\alpha$-SMA and fibronectin, respectively, and for ERK1/2 activation leading to the E-cadherin repression (Rhyu et al., 2005). These EMTrelated molecular events are mimicked by $\mathrm{H}_{2} \mathrm{O}_{2}$ treatment, with the exception of Smad2 phosphorylation, and are strictly dependent on ERK1/2 activation (Rhyu et al., 2005). TGF- $\beta$ has also been correlated to ROS-dependent EMT induction through regulation of ferritin heavy chain (FHC) levels (Zhang et al., 2009). The expression of a key iron storage protein FHC was decreased upon TGF- $\beta$ stimulation, thereby causing an increase in the intracellular labile iron pool (LIP). An increase of LIP level promoted a strong enhancement in ROS intracellular content and a ROS-dependent activation of p38, ultimately leading to the mesenchymal phenotype. ROS elimination, as well as FHC overexpression, clearly abrogated the LIP increase and resulted in EMT suppression, suggesting that TGF- $\beta$ induced EMT is dependent on ROS production, as mediated by an increase of LIP level (Zhang et al., 2009).

\section{CONCLUSION}

In this review, we have summarized recent findings about the role of ROS in cancer metastasis. Many evidences clearly support that the ROS contribute to tumor malignancy by participating in molecular and cellular events involving the regulation of signaling pathways and in the transcriptional activities that induce cell migration, invasion, and EMT. Having said that, more studies definitely need to elucidate a solid mechanism of how ROS control tumor invasion and metastasis. There is no doubt that understanding how the imbalance of the ROS regulation affects metastatic tendency in cancer cells helps the development of strategies to overcome tumor metastasis.

\section{ACKNOWLEDGMENTS}

This study was supported by the Drug Target Validation Program (2011-0030195) and the Research Center for Cellular Homeostasis (2012R1A5A1048236) of the National Research Foundation funded by the Korean government (Ministry of Education and Science Technology). This work was partly supported by the intramural GT5 grants from Ewha Womans University. D. J. Lee was supported by a RP-Grant 2011 of Ewha Womans University.

\section{REFERENCES}

Anastasiadis, P.Z., and Reynolds, A.B. (2000). The p120 catenin family: complex roles in adhesion, signaling and cancer. J. Cell Sci. 113 (Pt 8), 1319-1334.

Arthur, J.R. (2000). The glutathione peroxidases. Cell. Mol. Life Sci $57,1825-1835$

Bae, Y.S., Oh, H., Rhee, S.G., and Yoo, Y.D. (2011). Regulation of reactive oxygen species generation in cell signaling. Mol. Cells 32, 491-509.

Barnett, P., Arnold, R.S., Mezencev, R., Chung, L.W., Zayzafoon, M., and Odero-Marah, V. (2011). Snail-mediated regulation of reactive oxygen species in ARCaP human prostate cancer cells. Biochem. Biophys. Res. Commun. 404, 34-39.

Baum, B., Settleman, J., and Quinlan, M.P. (2008). Transitions between epithelial and mesenchymal states in development and disease. Semin. Cell Dev. Biol. 19, 294-308.

Binker, M.G., Binker-Cosen, A.A., Richards, D., Oliver, B., and Cosen-Binker, L.I. (2009). EGF promotes invasion by PANC-1 cells through Rac1/ROS-dependent secretion and activation of MMP-2. Biochem. Biophys. Res. Commun. 379, 445-450.

Brazzolotto, X., Gaillard, J., Pantopoulos, K., Hentze, M.W., and Moulis, J.M. (1999). Human cytoplasmic aconitase (Iron regulatory protein 1) is converted into its [3Fe-4S] form by hydrogen peroxide in vitro but is not activated for iron-responsive element binding. J. Biol. Chem. 274, 21625-21630.

Brenneisen, P., Sies, H., and Scharffetter-Kochanek, K. (2002). Ultraviolet-B irradiation and matrix metalloproteinases: from induction via signaling to initial events. Ann. N.Y. Acad. Sci. 973, 31-43.

Brooks, S.A., Lomax-Browne, H.J., Carter, T.M., Kinch, C.E., and Hall, D.M. (2010). Molecular interactions in cancer cell metastasis. Acta Histochem. 112, 3-25.

Broom, O.J., Massoumi, R., and Sjolander, A. (2006). Alpha2beta1 integrin signalling enhances cyclooxygenase-2 expression in intestinal epithelial cells. J. Cell. Physiol. 209, 950-958.

Cairo, G., Castrusini, E., Minotti, G., and Bernelli-Zazzera, A. (1996). Superoxide and hydrogen peroxide-dependent inhibition of iron regulatory protein activity: a protective stratagem against oxidative injury. FASEB J. 10, 1326-1335.

Cannito, S., Novo, E., Compagnone, A., Valfre di Bonzo, L., Busletta, C., Zamara, E., Paternostro, C., Povero, D., Bandino, A. Bozzo, F., et al. (2008). Redox mechanisms switch on hypoxiadependent epithelial-mesenchymal transition in cancer cells. Carcinogenesis 29, 2267-2278.

Cannito, S., Novo, E., di Bonzo, L.V., Busletta, C., Colombatto, S. and Parola, M. (2010). Epithelial-mesenchymal transition: from molecular mechanisms, redox regulation to implications in human health and disease. Antioxid. Redox Signal. 12, 1383-1430.

Chiarugi, P., and Fiaschi, T. (2007). Redox signalling in anchoragedependent cell growth. Cell. Signal. 19, 672-682.

Chiarugi, P., Pani, G., Giannoni, E., Taddei, L., Colavitti, R., Raugei, G., Symons, M., Borrello, S., Galeotti, T., and Ramponi, G. (2003). Reactive oxygen species as essential mediators of cell adhesion: the oxidative inhibition of a FAK tyrosine phosphatase is required for cell adhesion. J. Cell Biol. 161, 933-944.

Chiu, W.T., Shen, S.C., Chow, J.M., Lin, C.W., Shia, L.T., and Chen, Y.C. (2010). Contribution of reactive oxygen species to migration/invasion of human glioblastoma cells U87 via ERK-dependent COX-2/PGE(2) activation. Neurobiol. Dis. 37, 118-129.

Comito, G., Calvani, M., Giannoni, E., Bianchini, F., Calorini, L., Torre, E., Migliore, C., Giordano, S., and Chiarugi, P. (2011) HIF-1alpha stabilization by mitochondrial ROS promotes Metdependent invasive growth and vasculogenic mimicry in melanoma cells. Free Radic. Biol. Med. 51, 893-904.

Curran, S., Dundas, S.R., Buxton, J., Leeman, M.F., Ramsay, R., and Murray, G.I. (2004). Matrix metalloproteinase/tissue inhibitors of matrix metalloproteinase phenotype identifies poor prognosis colorectal cancers. Clin. Cancer Res. 10, 8229-8234.

Dong, R., Wang, Q., He, X.L., Chu, Y.K., Lu, J.G., and Ma, Q.J. (2007). Role of nuclear factor kappa $B$ and reactive oxygen species in the tumor necrosis factor-alpha-induced epithelialmesenchymal transition of MCF-7 cells. Braz. J. Med. Biol. Res. 40, 1071-1078.

Giannoni, E., Parri, M., and Chiarugi, P. (2012). EMT and oxidative stress: a bidirectional interplay affecting tumor malignancy. Antioxid. Redox Signal. 16, 1248-1263.

Gloire, G., Legrand-Poels, S., and Piette, J. (2006). NF-kappaB activation by reactive oxygen species: fifteen years later. Biochem. Pharmacol. 72, 1493-1505.

Gregg, D., de Carvalho, D.D., and Kovacic, H. (2004). Integrins and coagulation: a role for ROS/redox signaling? Antioxid. Redox Signal. 6, 757-764.

Ho, B.Y., Wu, Y.M., Chang, K.J., and Pan, T.M. (2011). Dimerumic acid inhibits SW620 cell invasion by attenuating $\mathrm{H}(2) \mathrm{O}(2)$ - 
mediated MMP-7 expression via JNK/C-Jun and ERK/C-Fos activation in an AP-1-dependent manner. Int. J. Biol. Sci. 7, 869880.

Honore, S., Kovacic, H., Pichard, V., Briand, C., and Rognoni, J.B. (2003). Alpha2beta1-integrin signaling by itself controls G1/S transition in a human adenocarcinoma cell line (Caco-2): implication of NADPH oxidase-dependent production of ROS. Exp. Cell Res. 285, 59-71.

Hurd, T.R., DeGennaro, M., and Lehmann, R. (2012). Redox regulation of cell migration and adhesion. Trends Cell Biol. 22, 107-115.

Inumaru, J., Nagano, O., Takahashi, E., Ishimoto, T., Nakamura, S., Suzuki, Y., Niwa, S., Umezawa, K., Tanihara, H., and Saya, H. (2009). Molecular mechanisms regulating dissociation of cell-cell junction of epithelial cells by oxidative stress. Genes Cells 14 703-716.

Kheradmand, F., Werner, E., Tremble, P., Symons, M., and Werb, Z. (1998). Role of Rac1 and oxygen radicals in collagenaseexpression induced by cell shape change. Science 280, 898-902.

Kim, M.H., Yoo, H.S., Kim, M.Y., Jang, H.J., Baek, M.K., Kim, H.R., Kim, K.K., Shin, B.A., Ahn, B.W., and Jung, Y.D. (2007). Helicobacter pylori stimulates urokinase plasminogen activato receptor expression and cell invasiveness through reactive oxygen species and NF-kappaB signaling in human gastric carcinoma cells. Int. J. Mol. Med. 19, 689-697.

Lambeth, J.D. (2007). Nox enzymes, ROS, and chronic disease: an example of antagonistic pleiotropy. Free Radic. Biol. Med. 43, 332-347.

Lander, H.M., Ogiste, J.S., Teng, K.K., and Novogrodsky, A. (1995). p21 ras as a common signaling target of reactive free radicals and cellular redox stress. J. Biol. Chem. 270, 21195-21198.

Lee, S.B., Bae, I.H., Bae, Y.S., and Um, H.D. (2006). Link between mitochondria and NADPH oxidase 1 isozyme for the sustained production of reactive oxygen species and cell death. J. Biol. Chem. 281, 36228-36235.

Lee, K.H., Kim, S.W., and Kim, J.R. (2009). Reactive oxygen species regulate urokinase plasminogen activator expression and cell invasion via mitogen-activated protein kinase pathways after treatment with hepatocyte growth factor in stomach cancer cells. J. Exp. Clin. Cancer Res. 28, 73 .

Lin, M.T., Yen, M.L., Lin, C.Y., and Kuo, M.L. (2003). Inhibition of vascular endothelial growth factor-induced angiogenesis by resveratrol through interruption of Src-dependent vascular endothelial cadherin tyrosine phosphorylation. Mol. Pharmacol. 64, 1029-1036.

Lowther, W.T., and Haynes, A.C. (2011). Reduction of cysteine sulfinic acid in eukaryotic, typical 2-Cys peroxiredoxins by sulfiredoxin. Antioxid. Redox Signal. 15, 99-109.

Lukaszewicz-Zajac, M., Mroczko, B., and Szmitkowski, M. (2011). Gastric cancer - the role of matrix metalloproteinases in tumor progression. Clin. Chim. Acta 412, 1725-1730.

Meyer, T., and Hart, I.R. (1998). Mechanisms of tumour metastasis. Eur. J. Cancer 34, 214-221

Monaghan-Benson, E., and Burridge, K. (2009). The regulation of vascular endothelial growth factor-induced microvascular permeability requires Rac and reactive oxygen species. J. Biol. Chem. 284, 25602-25611.

Moskovitz, J., Berlett, B.S., Poston, J.M., and Stadtman, E.R. (1997). The yeast peptide-methionine sulfoxide reductase functions as an antioxidant in vivo. Proc. Natl. Acad. Sci. USA 94, 9585-9589.

Nelson, K.K., and Melendez, J.A. (2004). Mitochondrial redox control of matrix metalloproteinases. Free Radic. Biol. Med. 37, 768784.

Nigam, S., Weston, C.E., Liu, C.H., and Simon, E.E. (1998). The actin cytoskeleton and integrin expression in the recovery of cell adhesion after oxidant stress to a proximal tubule cell line (JTC12). J. Am. Soc. Nephrol. 9, 1787-1797.

Nishikawa, M. (2008). Reactive oxygen species in tumor metastasis. Cancer Lett. 266, 53-59.

Nwariaku, F.E., Liu, Z., Zhu, X., Nahari, D., Ingle, C., Wu, R.F., Gu, Y., Sarosi, G., and Terada, L.S. (2004). NADPH oxidase mediates vascular endothelial cadherin phosphorylation and endothelial dysfunction. Blood 104, 3214-3220.

Pani, G., Colavitti, R., Bedogni, B., Anzevino, R., Borrello, S., and Galeotti, T. (2000). A redox signaling mechanism for density-de- pendent inhibition of cell growth. J. Biol. Chem. 275, 38891-38899.

Pelicano, H., Lu, W., Zhou, Y., Zhang, W., Chen, Z., Hu, Y., and Huang, P. (2009). Mitochondrial dysfunction and reactive oxygen species imbalance promote breast cancer cell motility through a CXCL14-mediated mechanism. Cancer Res. 69, 2375-2383.

Peppelenbosch, M.P., Qiu, R.G., de Vries-Smits, A.M., Tertoolen, L.G., de Laat, S.W., McCormick, F., Hall, A., Symons, M.H., and Bos, J.L. (1995). Rac mediates growth factor-induced arachidonic acid release. Cell 81, 849-856.

Pervaiz, S., and Clement, M.V. (2007). Superoxide anion: oncogenic reactive oxygen species? Int. J. Biochem. Cell Biol. 39, 1297-1304.

Rabbani, S.A., and Xing, R.H. (1998). Role of urokinase (UPA) and its receptor (UPAR) in invasion and metastasis of hormonedependent malignancies. Int. J. Oncol. 12, 911-920.

Reddy, S.P., and Mossman, B.T. (2002). Role and regulation of activator protein-1 in toxicant-induced responses of the lung. Am. J. Physiol. Lung Cell Mol. Physiol. 283, L1161-1178.

Reuning, U., Sperl, S., Kopitz, C., Kessler, H., Kruger, A., Schmitt, M., and Magdolen, V. (2003). Urokinase-type plasminogen activator (UPA) and its receptor (UPAR): development of antagonists of UPA/UPAR interaction and their effects in vitro and in vivo. Curr. Pharm. Des. 9, 1529-1543.

Rhee, S.G., Kang, S.W., Jeong, W., Chang, T.S., Yang, K.S., and Woo, H.A. (2005). Intracellular messenger function of hydrogen peroxide and its regulation by peroxiredoxins. Curr. Opin. Cell Biol. 17, 183-189.

Rhyu, D.Y., Yang, Y., Ha, H., Lee, G.T., Song, J.S., Uh, S.T., and Lee, H.B. (2005). Role of reactive oxygen species in TGF-beta1induced mitogen-activated protein kinase activation and epithelial-mesenchymal transition in renal tubular epithelial cells. J. Am. Soc. Nephrol. 16, 667-675.

Sangrar, W., Gao, Y., Scott, M., Truesdell, P., and Greer, P.A. (2007). Fer-mediated cortactin phosphorylation is associated with efficient fibroblast migration and is dependent on reactive oxygen species generation during integrin-mediated cell adhesion. Mol. Cell. Biol. 27, 6140-6152.

Shinohara, M., Adachi, Y., Mitsushita, J., Kuwabara, M., Nagasawa, A., Harada, S., Furuta, S., Zhang, Y., Seheli, K., Miyazaki, H., et al. (2010). Reactive oxygen generated by NADPH oxidase 1 (Nox1) contributes to cell invasion by regulating matrix metalloprotease-9 production and cell migration. J. Biol. Chem. 285, $4481-4488$.

Sorby, M., and Ostman, A. (1996). Protein-tyrosine phosphatasemediated decrease of epidermal growth factor and plateletderived growth factor receptor tyrosine phosphorylation in high cell density cultures. J. Biol. Chem. 271, 10963-10966.

Taddei, M.L., Parri, M., Mello, T., Catalano, A., Levine, A.D., Raugei, G., Ramponi, G., and Chiarugi, P. (2007). Integrin-mediated cell adhesion and spreading engage different sources of reactive oxygen species. Antioxid. Redox Signal. 9, 469-481.

Thews, O., Lambert, C., Kelleher, D.K., Biesalski, H.K., Vaupel, P., and Frank, J. (2009). Impact of reactive oxygen species on the expression of adhesion molecules in vivo. Adv. Exp. Med. Biol. $645,95-100$

Thiery, J.P., and Sleeman, J.P. (2006). Complex networks orchestrate epithelial-mesenchymal transitions. Nat. Rev. Mol. Cell Biol. 7, 131-142.

Tobar, N., Villar, V., and Santibanez, J.F. (2010). ROS-NFkappaB mediates TGF-beta1-induced expression of urokinase-type plasminogen activator, matrix metalloproteinase- 9 and cell invasion. Mol. Cell Biochem. 340, 195-202.

Tran, H., Maurer, F., and Nagamine, Y. (2003). Stabilization of urokinase and urokinase receptor mRNAs by HuR is linked to its cytoplasmic accumulation induced by activated mitogen-activated protein kinase-activated protein kinase 2 . Mol. Cell. Biol. 23, 7177-7188.

Ushio-Fukai, M. (2009). Compartmentalization of Redox Signaling Through NADPH Oxidase-Derived ROS. Antioxid. Redox Signal. 11, 1289-1299.

van Buul, J.D., Anthony, E.C., Fernandez-Borja, M., Burridge, K., and Hordijk, P.L. (2005). Proline-rich tyrosine kinase 2 (Pyk2) mediates vascular endothelial-cadherin-based cell-cell adhesion by regulating beta-catenin tyrosine phosphorylation. J. Biol. Chem. 280, 21129-21136.

van Wetering, S., van Buul, J.D., Quik, S., Mul, F.P., Anthony, E.C., 
ten Klooster, J.P., Collard, J.G., and Hordijk, P.L. (2002). Reactive oxygen species mediate Rac-induced loss of cell-cell adhesion in primary human endothelial cells. J. Cell Sci. 115, 18371846.

Werner, E., and Werb, Z. (2002). Integrins engage mitochondrial function for signal transduction by a mechanism dependent on Rho GTPases. J. Cell Biol. 158, 357-368.

Woo, C.H., Eom, Y.W., Yoo, M.H., You, H.J., Han, H.J., Song, W.K., Yoo, Y.J., Chun, J.S., and Kim, J.H. (2000). Tumor necrosis factor-alpha generates reactive oxygen species via a cytosolic phospholipase A2-linked cascade. J. Biol. Chem. 275, 3235732362.

Wu, R., Coniglio, S.J., Chan, A., Symons, M.H., and Steinberg, B.M. (2007). Up-regulation of Rac1 by epidermal growth factor mediates COX-2 expression in recurrent respiratory papillomas. Mol. Med. 13, 143-150.

Yamaoka-Tojo, M., Ushio-Fukai, M., Hilenski, L., Dikalov, S.I., Chen, Y.E., Tojo, T., Fukai, T., Fujimoto, M., Patrushev, N.A., Wang, N., et al. (2004). IQGAP1, a novel vascular endothelial growth factor receptor binding protein, is involved in reactive oxygen species- dependent endothelial migration and proliferation. Circ. Res. 95, 276-283.

Yamaoka-Tojo, M., Tojo, T., Kim, H.W., Hilenski, L., Patrushev, N.A., Zhang, L., Fukai, T., and Ushio-Fukai, M. (2006). IQGAP1 mediates VE-cadherin-based cell-cell contacts and VEGF signaling at adherence junctions linked to angiogenesis. Arterioscler. Thromb. Vasc. Biol. 26, 1991-1997.

Yang, J.Q., Zhao, W., Duan, H., Robbins, M.E., Buettner, G.R., Oberley, L.W., and Domann, F.E. (2001). v-Ha-RaS oncogene upregulates the $92-\mathrm{kDa}$ type IV collagenase (MMP-9) gene by increasing cellular superoxide production and activating NFkappaB. Free Radic. Biol. Med. 31, 520-529.

Yang, S.H., Sharrocks, A.D., and Whitmarsh, A.J. (2003). Transcriptional regulation by the MAP kinase signaling cascades. Gene 320, 3-21.

Zhang, K.H., Tian, H.Y., Gao, X., Lei, W.W., Hu, Y., Wang, D.M., Pan, X.C., Yu, M.L., Xu, G.J., Zhao, F.K., et al. (2009). Ferritin heavy chain-mediated iron homeostasis and subsequen increased reactive oxygen species production are essential for epithelial-mesenchymal transition. Cancer Res. 69, 5340-5348. 